
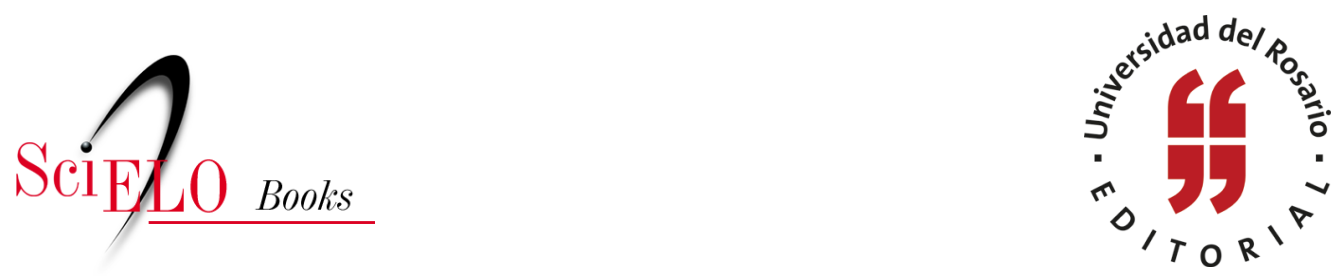

\title{
Introducción \\ Reflexiones en torno a la pregunta por la educación legal clínica y su enfoque de interés público
}

\author{
Beatriz Londoño Toro
}

\section{SciELO Books / SciELO Livros / SciELO Libros}

LODOÑO TORO, B. Introducción. Reflexiones en torno a la pregunta por la educación legal clínica y su enfoque de interés público. In: Educación legal clínica y litigio estratégico en Iberoamérica [online]. Bogotá: Editorial Universidad del Rosario, 2015, pp. 1-7. Textos de jurisprudencia collection. ISBN 978-958-738-624-0. https://doi.org/10.7476/9789587386240.0001.

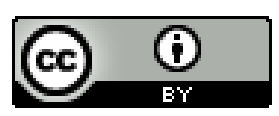

All the contents of this work, except where otherwise noted, is licensed under a Creative Commons Attribution 4.0 International license.

Todo o conteúdo deste trabalho, exceto quando houver ressalva, é publicado sob a licença Creative Commons Atribição 4.0.

Todo el contenido de esta obra, excepto donde se indique lo contrario, está bajo licencia de la licencia Creative Commons Reconocimento 4.0. 


\section{Introducción \\ Reflexiones en torno a la pregunta por la educación legal clínica y su enfoque de interés público}

Tan importante como precisar el concepto de interés público será definir cómo hemos de enfocar la defensa de ese interés y qué lugar le corresponderá a la comunidad en el desarrollo

de esa tarea.

Víctor Abramovich

En el año 1999, el entonces decano de la Facultad de Jurisprudencia de la Universidad del Rosario, doctor Marco Gerardo Monroy Cabra, encargó a varios profesores la misión de indagar sobre la educación legal clínica en otros países y solicitó especialmente contactar a la Universidad Diego Portales, en Chile, donde se tenía conocimiento del surgimiento de la Red Sudamericana de Clínicas de Interés Público, liderada por el profesor Felipe González.

El objetivo era claro: se quería iniciar en la Universidad del Rosario una nueva experiencia que empezara a impactar socialmente y a transformar desde adentro la forma como se enseñaba el derecho. Con apoyo institucional se empezó el camino de aprendizajes y relaciones académicas que permitió fundar en Colombia la primera clínica jurídica de interés público: el Grupo de Acciones Públicas (GAP), que ha permanecido durante 15 años liderando el tema, formando a los futuros profesores de otras clínicas y sistematizando, evaluando y reinventando esta experiencia cada vez que hay oportunidad para ello.

A diferencia de otras clínicas iberoamericanas, el camino no empezó en Estados Unidos ni en sus universidades; se inició el recorrido desde el Sur, en Santiago de Chile, en diálogo con las universidades latinoamericanas, inicialmente, y en los últimos años ha habido un acercamiento interesante con clínicas norteamericanas de derechos humanos, con el movimiento pro 
bono, con el Global Alliance For Justice Education (GAJE) y con las clínicas españolas. El libro que se presenta es el resultado de una investigación propuesta como resultado de año sabático, para volver a los orígenes de este debate, propiciar un reencuentro con los actores de la educación legal clínica en Iberoamérica y, ante todo, para resaltar sus voces, sus recomendaciones, los logros, los fracasos y el gran esfuerzo de docentes y estudiantes en muchas universidades de la región.

\section{Un concepto inicial de clínicas jurídicas y litigio estratégico}

El concepto de clínicas jurídicas — que se desarrolla ampliamente en este libro- tiene su origen a comienzos del siglo xx y se atribuye a Jerome Frank, en Estados Unidos, la denominación y la argumentación crítica que desde el realismo jurídico se hizo a la forma como se enseñaba el derecho. En el trabajo denominado “¿Why Not a Legal Clinic?”, la propuesta inicial era copiar del modelo de educación de las facultades de medicina elementos tan valiosos como el trabajo directo con casos reales y los aspectos prácticos de la docencia. Pero realmente fue en los años sesenta cuando se difunde y promueve en mayor medida esta forma de educación y se asocia a criterios de justicia social (Blázquez Martín, 2006). Se señala entonces que la educación legal clínica contribuye a la enseñanza de habilidades jurídicas en un contexto reflexivo de justicia social (García Añón, 2013b, p. 35).

En los años noventa se complementa el método con criterios más específicos que apuntan al desarrollo de competencias y exigencias de la docencia clínica, como la necesidad de enfrentar a los estudiantes a problemas y situaciones reales que viven los abogados, la exigencia de trabajo de los estudiantes para solucionar dichos problemas, la interacción de los estudiantes con otras personas para buscar resolver el problema y la tipología de caos que apuntan a temas sociales y de interés público, priorizando la atención gratuita de personas que lo requieren, todo esto en un entorno de construcción de conocimiento y evaluación permanente, liderado por los docentes clínicos o supervisores (Blázquez Martín, 2006).

El concepto de litigio estratégico — que vamos a desarrollar en profundidad en el segundo capítulo — ha sido medular desde los inicios del movimiento de clínicas de interés público en Latinoamérica. Para entenderlo debemos acercarnos a sus elementos: en primer lugar: ¿cómo lo diferenciamos del litigio tradicional? Hemos agregado dos adjetivos a la noción clásica de litigio 
estratégico para diferenciarla del trabajo habitual que pueden desarrollar los abogados en ciertos casos. Para que exista este litigio se requiere trascender del caso particular o individual hacia la repercusión o impacto colectivo. De igual forma, es necesario mirar el propósito de este litigio, y este debe enfocarse en ampliar o fortalecer los estándares de protección y garantía de derechos humanos; nunca podrá enfocarse en la regresividad. Por esto lo hemos denominado progresista o garantista (Santos, 2001, p. 85).

Luego debemos entender que este litigio tiene repercusiones o impactos que inciden en su denominación. Podemos observar cómo se le denomina litigio estructural o generador de cambios jurídicos, sociopolíticos o pedagógicos.

Se trata de trabajar con casos de impacto amplio o casos emblemáticos o, incluso, apoyarse en los llamados casos testigo (casos individuales que ejemplifican graves vulneraciones a derechos humanos). En esta labor es indispensable, además de la estrategia jurídica y política, el apoyo de los medios de comunicación y la labor pedagógica y de divulgación del caso, sus resultados y su seguimiento.

Finalmente la pregunta apunta al cómo y a quiénes realizan este litigio. En la mirada de los instrumentos del litigio podemos precisar que no se realiza solamente en escenarios judiciales (aunque es el tipo de litigio más conocido); también se puede realizar litigio estratégico ante entidades administrativas o particulares, siempre y cuando se utilice el derecho y especialmente los derechos humanos como objeto de la reclamación o contenido de la labor específica. En relación con el tipo de actores de este litigio, podemos finalmente señalar que el abanico de posibilidades es enorme. Se puede hacer este litigio desde organizaciones sociales, ONG, clínicas jurídicas, bufetes de abogados que trabajan en pro bono o entidades estatales, como las defensorías del pueblo, por ejemplo.

\section{Litigio estratégico e interés público}

El término en torno al cual gira todo el debate del litigio estratégico y la educación legal clínica es el denominado interés público. Pero, ¿qué es lo público y cómo se caracteriza?

Llama la atención que este concepto no es unívoco y se usa desde diferentes enfoques disciplinarios. Pueden identificarse varios sentidos en su utilización cotidiana: en primer lugar se entiende por tal lo común y general; es igualmente sinónimo de interés político, estatal y social, y finalmente hace 
referencia a lo visible y manifiesto (Minteriaga Garaban, 2009). “[...] lo público es fundamentalmente una construcción que se disputa en un reino de referencias simbólicas [...]. En realidad aquello que se vuelve público o que deja de serlo es el resultado de un proceso de discusión, de enfrentamiento, de diferencia y de acuerdo" (p.33).

Desde la nueva mirada propuesta por las organizaciones sociales y por los teóricos del tema, lo público se asocia a la construcción de intereses colectivos en el marco de una democracia incluyente que garantice la equidad y la participación de las organizaciones y de los ciudadanos. En América Latina es cada vez más clara la distinción entre lo público y lo estatal, y desde el trabajo de litigio estratégico este ha sido uno de los pilares fundacionales.

El concepto permite construir un puente entre sociedad y Estado, entre lo privado y lo estatal, un espacio que denomina las arenas públicas, donde se busca movilizar nuevas formas de acción, representación, negociación e interlocución en torno a una agenda social construida sin monopolios y a exigencias concretas en materia económica, jurídica, política y social (Cunill Grau, 1997, p. 58).

Uno de los objetivos centrales del trabajo de ong, fundaciones y universidades es permitir el debate público sobre temas y problemas que durante mucho tiempo permanecieron ocultos, vedados al análisis y a la evidencia de su impacto colectivo.

El camino recorrido en las últimas décadas muestra avances significativos en el surgimiento de organizaciones sociales que inicialmente plantean un carácter antiestatalista y luego asumen su papel en el concepto de lo público, proponiendo los debates y reclamos en torno a los derechos colectivos; de igual forma han logrado colonizar espacios antes limitados solo a los abogados y funcionarios, como los parlamentos (a través del ejercicio del lobby parlamentario), los tribunales (a través del litigio estratégico), y el diseño, seguimiento y evaluación de políticas públicas en todos los campos del interés público.

Un debate interesante se plantea al examinar la relación entre interés público y derechos humanos, en la que consideramos que se trata de dos nociones complementarias y directamente ligadas en la medida que se avanza en la defensa de derechos económicos, sociales, culturales y colectivos. Al respecto señala González: "por lo mismo, la noción de interés público ya no se nos presenta como un elemento que limita los derechos humanos, sino que adquiere una estrecha conexión con estos, en la medida en que su protección 
aparece como uno de los aspectos centrales de la salvaguarda del interés público" (González Morales, 2004, p. 23).

En los estudios sobre educación legal clínica y litigio estratégico, el concepto central que vamos a encontrar es el de derecho de interés público. El concepto surge en Estados Unidos en la década de los sesenta del siglo pasado. No se trata de una nueva rama del derecho, sino de una forma diferente de abordar las herramientas jurídicas para defender intereses de los más desfavorecidos, superar las dificultades que se tienen en el acceso a la justicia para los más pobres y asumir causas en defensa de derechos civiles, derechos colectivos, derechos de género, entre muchas otras posibilidades. Este concepto tiene connotaciones culturales y políticas que le imprimen diversas prioridades y formas de ejercicio según la realidad a la cual se aplica (Rekosh, 2001).

En el año 1997 se realizó un simposio en Durban y allí se establecieron las siguientes prioridades:

a) Acceso a la justicia: es un tema central, en especial para aquellos sectores que carecen de recursos.

b) Educación legal clínica: como una de las contribuciones más importantes para el proceso de formación de nuevos abogados de interés público en la región.

c) Street law programs: buscan desmitificar el ejercicio del derecho y emplear la educación como una herramienta para la formación jurídica y crítica de la población.

d) Litigio de interés público: es la posibilidad de realización de litigio de alto impacto utilizando herramientas creativas en defensa de los derechos humanos y el interés público. Aún tiene debilidades y las más graves son los obstáculos que el mismo sistema jurídico establece.

e) Trabajo pro bono: estrategias de trabajo de interés público desde las firmas de abogados, a través de la donación de su tiempo y asesoría para estas causas.

f) Campañas: se estima prioritario el apoyo de medios de comunicación y el trabajo de lobby legislativo (legislative advocacy).

g) Estrategias de defensa de los derechos de las mujeres.

h) Estrategias para el litigio ante organismos internacionales (Rekosh, 2001, p. 4) 
En síntesis podría señalarse que el derecho de interés público tiene tres prioridades: acceso a la justicia, reformas normativas y de políticas públicas y empoderamiento político para generar cambios o incidir en el fortalecimiento de los derechos humanos.

Son muchas las preguntas que este trabajo busca abordar desde el punto de partida: ¿qué tipo de educación legal clínica tenemos y hacia dónde podemos avanzar? ¿Cómo encuadrar en los procesos de educación legal clínica el enfoque de interés público y derechos humanos? ¿Qué ha pasado en la región iberoamericana y cuáles son las fortalezas, debilidades, retos y oportunidades de estas experiencias?

La experiencia y el aprendizaje en torno al significado y construcción de las clínicas jurídicas en América Latina y en España permite identificar elementos comunes y hacer precisiones conceptuales que facilitan - a quienes comienzan el camino - tener claras las bases y los orígenes, pero también los derroteros. No existe una única forma de desarrollar la educación legal clínica; son numerosos los modelos posibles, la creatividad de los docentes y la innovación pedagógica es enorme en este tema.

Desde el punto de vista metodológico este proyecto se basó en la triangulación de información obtenida, en primer lugar, a través de la revisión de las fuentes teóricas documentales en los temas que se abordan. Además se aplicaron entrevistas semiestructuradas con el objetivo de examinar la percepción de los docentes clínicos en Argentina, Colombia, México, España y Perú; ${ }^{1}$ se complementó esta información con la aplicación y análisis de una encuesta dirigida a estudiantes o ex integrantes de clínicas jurídicas en la región. Dicha encuesta se aplicó entre los meses de marzo y mayo de 2013 a través de una herramienta virtual denominada Survey Monkey. Finalmente

${ }^{1}$ Los docentes entrevistados fueron:

Argentina: Pablo Asa (Clínica cels-Caref en Buenos Aires), Diego Morales (cels en Buenos Aires), Juan Picolotti (Cedha en Buenos Aires) y Mariela Puga (Universidad de Córdoba). Chile: Felipe González (Universidades Diego Portales en Santiago de Chile y Carlos III de Madrid), Elena Olea (Universidad Diego Portales en Santiago de Chile). Colombia: Érica Castro (Universidad de Medellín), Gabriela Recalde (Universidad Icesi), Isabel Goyes (Universidad de Nariño, en Pasto), Lucas Correa (Universidad de Los Andes). España: Miguel García Añón (Universidad de Valencia), Ángeles Galiana (Universidad Rovira e Virgili en Tarragona), María del Carmen Barranco (Universidad Carlos III en Madrid), Antonio Madrid (Universidad de Barcelona). México: Gabriela Rodríguez (Litiga en México D.F.), Hernán Güllco (Universidad Torcuato di Tella). Perú: Miguel Grandez (Universidad San Marcos en Lima). 
se analizaron 72 encuestas aplicadas a los decanos de facultades de derecho de Colombia por el Ministerio de Justicia.

El ámbito geográfico de este trabajo, si bien hace referencia a Iberoamérica, se ha concentrado en el estudio de las clínicas de Argentina, Chile, Perú, Colombia, México y España. En relación con el periodo examinado, nos hemos concentrado en los últimos 20 años, que además es el periodo de nacimiento y evolución de las clínicas actuales.

En la primera parte de esta investigación se examina la relación entre la educación jurídica y la educación legal clínica Iberoamérica. Se considera que el proceso de construcción de las clínicas en la región es un hito en la educación jurídica iberoamericana y existen evidencias que permiten afirmarlo. En este capítulo se realiza una profundización sobre los momentos históricos en que surgen las clínicas de la región y se observa cómo se trata de historias paralelas que se fortalecieron por los intercambios de aprendizajes y experiencias a través de las redes.

Se estudian también las características de la educación legal clínica en Iberoamérica, la realidad y los problemas en la construcción de lineamientos para un modelo pedagógico en la región, la evolución de las clínicas hacia trabajos temáticos y especializados, y se finaliza el capítulo con una sistematización de los logros y las dificultades de la educación legal clínica en los países examinados.

El segundo capítulo explora las posibilidades de ejercicio del litigio estratégico desde las clínicas jurídicas en Iberoamérica. Se desarrolla el concepto de litigio estratégico o estructural y se examina la forma cómo inciden en dicha propuesta las alianzas con oNG y en general lo que se denomina alianzas estratégicas. Luego se pasa a una profundización sobre la agenda de las clínicas y los temas prioritarios de derechos humanos en Iberoamérica. Este examen se realiza a partir de casos reales que han trabajado las clínicas. Se concluye con los temas más fuertes y en los cuales podría decirse que se han realizado aportes significativos y con los temas débiles o inexistentes, que exigirían el surgimiento de nuevas clínicas y proyectos de investigación. 